\title{
DIRECT AND INDIRECT EFFECTS OF HERBIVORES ON NITROGEN DYNAMICS: VOLES IN RIPARIAN AREAS
}

\author{
Joseph M. Sirotnak and Nancy J. Huntly ${ }^{1}$ \\ Center for Ecological Research and Education, Idaho State University, Campus Box 8007, \\ Pocatello, Idaho 83209 USA
}

\begin{abstract}
Herbivores can directly increase nitrogen mobility by increasing the quality of organic matter entering the decomposition cycle, but they also may decrease nitrogen mobility by decreasing the biomass of high-nitrogen species in the plant community. We assessed effects of voles (Microtus) on nitrogen dynamics using exclosures in two riparian meadows (Crystal Bench and Blacktail Deer Creek) in Yellowstone National Park (USA). At both sites, the quantity of plant litter was decreased by herbivory following a vole population peak in 1992. At Crystal Bench, removal of voles caused a decrease in the nitrogen concentration and an increase in the $\mathrm{C}: \mathrm{N}$ ratio of plant litter over the four years of the study. The higher quality litter produced in the presence of voles at Crystal resulted in a larger pool of potentially mineralizable nitrogen in soil from control plots relative to soils from plots that had not been accessible to voles. At Crystal, vole removal did not cause a change in plant community composition. However, at Blacktail, after several years of vole exclusion, legumes became more common in exclosures than in control plots that were accessible to voles. Selective herbivory on high-nitrogen legumes kept the litter quality outside exclosures low, whereas higher legume biomass caused a decrease in C:N ratio of plant litter inside exclosures. The removal of voles at Blacktail caused a $15 \%$ increase in the fraction of the soil nitrogen that was rapidly mineralizable.

Our results show that voles increased nitrogen mobility, especially during and after population peaks. However, that increase was offset by decreases in nitrogen mineralization over longer periods when voles caused a decrease in high-quality plant litter produced by preferred forage plants, especially legumes. Thus, both the mechanisms by which voles affected nitrogen dynamics and the net effects of voles varied over time and space. The balance of direct and indirect effects may provide a general mechanistic explanation of whether herbivores increase or decrease the rate of nitrogen cycling.
\end{abstract}

Key words: herbivory; legumes; Microtus; mineralization; nitrogen cycling; nitrogen, potentially mineralizable; plant litter; riparian; soil organic matter; Trifolium; voles; Yellowstone National Park.

\section{INTRODUCTION}

Terrestrial herbivores often increase (McKendrick et al. 1980, Swank et al. 1981, Ruess and McNaughton 1987, Holland and Detling 1990, Shariff et al. 1994, Frank and Evans 1997, McNaughton et al. 1997), but sometimes decrease (Pastor et al. 1988, 1993, Ritchie et al. 1998), the rate of nitrogen cycling. The factors that determine whether herbivory has a net positive or negative effect on nitrogen cycling are not clear and are likely to vary in time and space. Studies that address the mechanisms by which herbivores affect nitrogen dynamics are needed to understand the net effects of herbivores on spatial and temporal patterns of nitrogen cycling.

Herbivores affect the rate of terrestrial nitrogen turnover largely by influencing the amount and quality of organic matter in the soil and on the soil surface (e.g., Ruess and McNaughton 1987, McNaughton et al. 1988,

Manuscript received 8 June 1998; revised 17 December 1998; accepted 19 December 1998; final version received 12 January 1999.

${ }^{1}$ Address correspondence to this author.
Holland and Detling 1990, Pastor et al. 1993). The size of the active pool of nitrogen in soil organic matter is an important control on nitrogen availability (Fig. 1). In general, the direct effects of herbivores on plants and on the physical environment, such as removing standing vegetation, disturbing soil, and depositing high-nitrogen waste products, accelerate nitrogen cycling by increasing the quality of the soil organic matter (Ruess and McNaughton 1987, Frank and Groffman 1998). Conversely, selective foraging by herbivores alters plant community composition, which indirectly decreases nitrogen cycling. Because herbivores selectively consume more palatable plants, increases in less palatable plant species change overall plant litter quality and ultimately reduce the quality of the soil organic matter; thus, net nitrogen mineralization is decreased (Pastor et al. 1988, 1993, McInnes et al. 1992). The direct effect, increased nitrogen cycling rate in the presence of herbivores, probably occurs in all ecosystems, but this effect may be overshadowed by the indirect decelerating effect, caused by changes in plant community composition, that often results from selective 

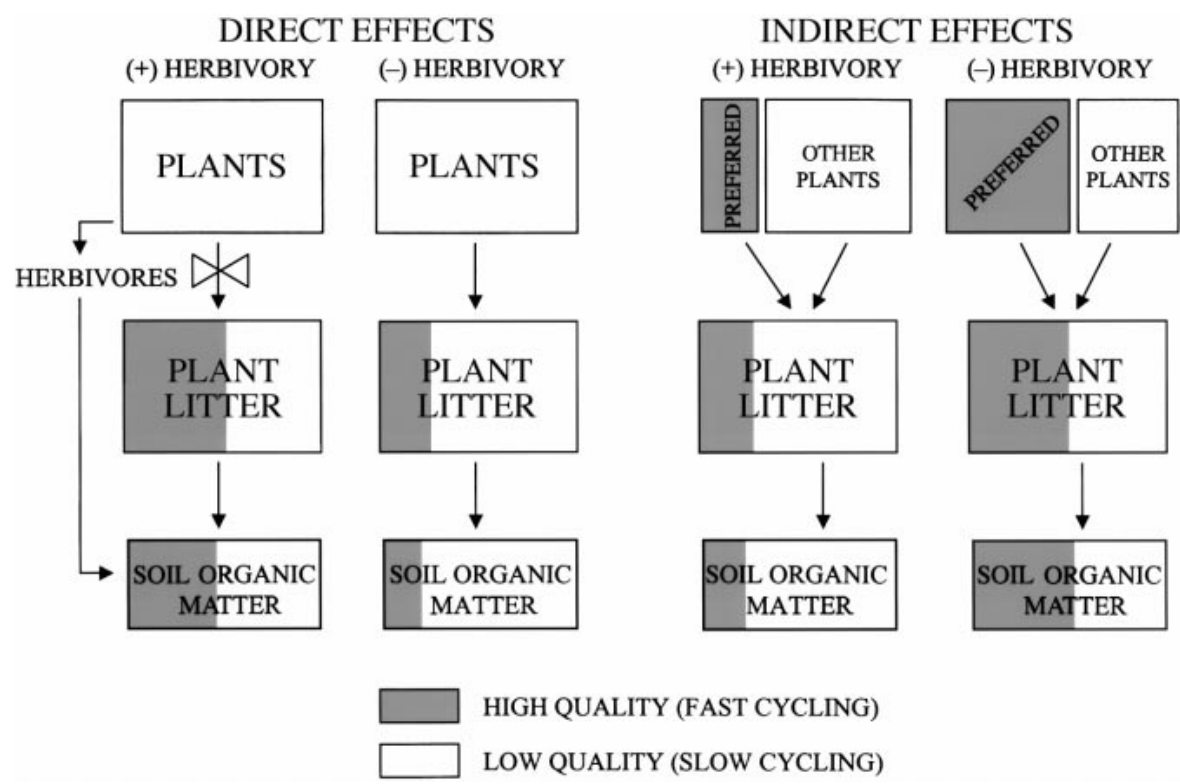

FIG. 1. Direct effects of herbivores tend to increase the proportion of the soil organic matter that is high quality (fast cycling) by increasing the quality of plant litter and by direct inputs of low C:N organic matter into the soil. Conversely, selective foraging may alter plant community composition such that the plant litter produced in the presence of herbivory is of lower quality (e.g., higher $\mathrm{C}: \mathrm{N}$ ratio, more recalcitrant secondary chemicals) than that produced in the absence of herbivory.

herbivory (Fig. 1). The relative importance of direct and indirect effects should vary with spatial and temporal patterns of herbivore abundance.

Herbivores can increase the quality of soil organic matter and directly increase the nitrogen cycling rate in several specific ways. In some cases, the concentration of nitrogen in herbivore biomass and waste products leads to a fertilizer effect, stimulating nitrogen mineralization and increasing nitrogen availibility (McKendrick et al. 1980, McNaughton et al. 1988, 1997, Frank et al. 1994, Shariff et al. 1994, Pastor et al. 1996, Frank and Evans 1997). Herbivory often increases the quality of the grazed plants by decreasing their C:N ratio (McNaughton 1979, Seastedt 1985, Seastedt et al. 1988, Merrill et al. 1994), which increases litter decomposition and stimulates net mineralization (Taylor et al. 1989, Frank et al. 1994, Scott and Binkley 1997, Frank and Groffman 1998). Herbivory-induced change in allocation of carbon and nitrogen in plant roots and shoots also tends to increase nitrogen turnover (Holland and Detling 1990, Merrill et al. 1994). Herbivores, by trampling, disturbing the soil surface, and removing vegetation, may prevent the buildup of plant litter and increase net nitrogen mineralization (Knapp and Seastedt 1986, Ruess 1987, Tardiff and Stanford 1998). These herbivore-caused increases in nitrogen mobility have been shown to increase primary productivity (McNaughton 1979, Bazely and Jefferies 1985, McNaughton et al. 1988, Frank and McNaughton 1992, Frank and Evans 1997).

Nevertheless, herbivores sometimes decelerate ni- trogen cycling. This appears to occur when herbivores cause changes in plant community composition. Selective foraging on high-quality plants, e.g., plants with a relatively low $\mathrm{C}: \mathrm{N}$ ratio or with low concentrations of recalcitrant chemicals, can decrease the abundance of these plants relative to plants of lower quality (McInnes et al. 1992, Ritchie et al. 1998). The relatively low-quality plant litter mineralizes nitrogen at a slower rate than would occur in the absence of herbivory (Pastor et al. 1988, 1993).

The objective of this study was to determine the effects of voles (Microtus, Rodentia: Microtinae) on nitrogen dynamics in riparian meadows in Yellowstone Park. Although much research has been done on the effects of ungulate herbivores, less is known about the effects of smaller animals on ecosystem processes. Voles are strict herbivores with high reproductive rates; their populations can fluctuate greatly both between and within years (Taitt and Krebs 1985). When populations are high, voles can consume much of the aboveground plant biomass (Summerhayes 1941, Batzli and Pitelka 1971, Moen et al. 1993, Virtanen et al. 1997). Thus, the effects of voles on nitrogen dynamics can be pulsed, or discontinuous, in time. Occasional high population densities may directly cause large pulses in nitrogen mobility. Conversely, chronic herbivory may indirectly lead to decreases in nitrogen mobility by causing changes in plant species composition.

We used fenced exclosures to assess the effects of voles on nitrogen dynamics. We hypothesized that nitrogen cycling would be slower in the absence of voles, 
TABle 1. Vegetation and soil fertility characteristics of the two study sites in northern Yellowstone Park, Wyoming, USA.

\begin{tabular}{lll}
\hline \hline \multicolumn{1}{c}{ Characteristics } & \multicolumn{1}{c}{ Blacktail } & \multicolumn{1}{c}{ Crystal } \\
\hline 1992 peak aboveground biomass $\left(\mathrm{g} / \mathrm{m}^{2}\right)$ & 530 & 477 \\
Dominant graminoids (relative biomass, \%) & $\begin{array}{l}\text { Carex spp. (35) } \\
\text { Calamagrostis canadensis (21) } \\
\text { Phleum pratense (9) }\end{array}$ & $\begin{array}{l}\text { Phleum pratense (38) } \\
\text { Carex spp. (6) }\end{array}$ \\
Dominant forbs (relative biomass, \%) & $\begin{array}{l}\text { Aster sibiricus }(7) \\
\text { Arnica chamissonis (7) }\end{array}$ & $\begin{array}{l}\text { Solidago canadensis (13) } \\
\text { Geranium richardsoni (11) } \\
\text { Epilobium augustifolium (9) }\end{array}$ \\
Soil nitrogen concentration (\% by mass) & 0.29 & 0.70 \\
Soil carbon:nitrogen (mass:mass) & 17.6 & 13.2
\end{tabular}

because studies in Yellowstone Park and elsewhere have suggested that herbivores do not affect plant species composition dramatically in heavily grazed ecosystems (Milchunas et al. 1989, Mack and Thompson 1982). Thus, we hypothesized that voles primarily affected nitrogen cycling by directly stimulating nitrogen flux pathways, for instance, by increasing quality of litter and depositing urine and feces. The incorporation of higher quality organic matter in the form of urine, feces, and low C:N plant litter should increase the quality of the soil organic matter in control plots, which are used by voles, relative to exclosures. Therefore, we expected that laboratory incubations would reveal that soil from control plots has a larger pool of rapidly mineralizable nitrogen than soil from vole exclosures.

\section{Methods}

\section{Study areas}

We studied the effects of voles on riparian meadows in northern Yellowstone Park $\left(110^{\circ} 42^{\prime} \mathrm{W}, 44^{\circ} 59^{\prime} \mathrm{N}\right)$, Wyoming, United States. The two study sites were chosen to represent physiographically different types of riparian landscape (Table 1). Blacktail Deer Creek is a third-order montane stream with a narrow, well-defined riparian area bounded by sagebrush and open forest uplands. The soil is heterogeneous, consisting of layers of old sandbars, muddy deposits, and cobble beds. Crystal Bench is a wet meadow below a series of small seeps feeding an intermittent stream that is usually dry by August. The soil at Crystal Bench is deep, rich, and of a mostly uniform loamy texture. The elevation of both sites is between 1600 and $1800 \mathrm{~m}$. Both sites were relatively free of woody vegetation and had evidence of voles. Pocket gophers (Thomomys talpoides) were present during the four years of the experiment, but few gopher mounds appeared on study plots during the experiment.

\section{Estimation of small-mammal population density}

Small-mammal populations were censused in the late summer of each year by live-trapping. At each exclosure site, we placed two live-trap mini-grids adjacent to the study plots. Each mini-grid consisted of three rows of three Sherman traps spaced $15 \mathrm{~m}$ apart and three rows of three coffee-can pitfall traps spaced 15 $\mathrm{m}$ apart, with the Sherman grid being offset $7.5 \mathrm{~m}$ diagonally to the pitfall grid. Sherman traps were baited with oats and peanut butter; pitfalls were not baited. Traps were checked every morning and evening for 4 $\mathrm{d}$, and captured animals were marked and released. To estimate small-mammal density, the total number of animals captured over the 4 -d period was entered into an equation that had previously been calibrated by regressing mini-grid captures on mark-recapture population estimates from large grids at several riparian sites in northern Yellowstone Park (R. Crabtree, unpublished data). The relative trap spacing in these large grids was the same as in the mini-grids, but the large grids consisted of 10 rows of 10 traps each. A separate regression equation was created for each common small-mammal species in the area. The resulting regression equation for Microtus had $R^{2}=0.85$. The mean of the regression estimates from the two mini-grids at each site was used as the density estimate of the site.

\section{Experimental design}

In the spring of 1992, we built eight vole exclosures at each of the two riparian meadow sites in the northern range of Yellowstone National Park. The exclosures were $5 \times 2.5 \mathrm{~m}$ rectangles constructed of $0.6-\mathrm{cm}$ mesh welded wire fence, extending from $15 \mathrm{~cm}$ below ground to a height of $45 \mathrm{~cm}$. We added $15 \mathrm{~cm}$ of aluminum flashing to the top of the welded wire to prevent small mammals from climbing over the fence. Each exclosure was paired with an unfenced (control) plot of the same size. Small mammals initially present in the exclosures were trapped and removed within the first month of the study.

\section{Vegetation sampling}

Aboveground plant biomass was measured in each plot during the period of peak biomass in late July or early August. In each plot, two strips of vegetation (0.1 $\times 0.5 \mathrm{~m}$ ) were clipped, sorted to species, dried, and weighed. Similarly, total standing dead biomass was measured in October of each year (except 1993). The mean biomass of the two strips was used in statistical procedures. The carbon and nitrogen concentration of 
plant litter was measured with a Carlo Erba CN1500 combustion $\mathrm{C}-\mathrm{H}-\mathrm{N}$ analyzer (CE Instruments, Milan, Italy).

\section{Soil incubations in the laboratory}

Potentially mineralizable nitrogen is the fraction of the organic nitrogen that is mineralized rapidly, or over an ecologically relevant time scale. The size of this pool is a function of the type of organic molecules in the soil; thus, it reflects the quality of the soil organic matter. The amount of potentially mineralizable nitrogen $\left(N_{0}\right)$ in soil can be roughly measured as the cumulative amount mineralized over a year-long laboratory incubation under conditions favoring optimal microbial activity (Stanford and Smith 1972). However, this cumulative total includes small amounts of nitrogen mineralized from more recalcitrant (i.e., relatively inactive) organic pools, and thus is not an accurate measure of rapidly mineralizable nitrogen. To more accurately assess $N_{0}$ in each soil sample, we used three nonlinear regression models (Deans et al. 1986). The three models hypothesize (1) a single pool of organic nitrogen mineralizing at a nonlinear, decreasing, rate, (2) a fast pool and a slow pool, both mineralizing at a nonlinear, decreasing, rate, and (3) a fast pool mineralizing at a nonlinear, decreasing, rate and a slow pool mineralizing at a constant rate:

$$
\begin{aligned}
& N_{t}=N_{0}\left(1-e^{-k t}\right) \\
& N_{t}=N_{0} S\left(1-e^{-h t}\right)+N_{0}(1-S)\left(1-e^{-k t}\right) \\
& N_{t}=N_{0}\left(1-e^{-k t}\right)+C t
\end{aligned}
$$

where $N_{t}$ is the cumulative nitrogen mineralized at time $t, N_{0}$ is the hypothetical pool size of potentially mineralizable nitrogen, and $t$ is time in weeks. In model $2, S$ and $1-S$ represent the size of the fast and slow mineralizing subpools, respectively, and $h$ and $k$ represent the rate constants for these pools. In model 3, $C$ is the size of the slow, constant pool.

Soil from two control plots at Crystal did not fit any of the three nonlinear models. In both cases and for all three models, either the iterations failed to converge on a least squares equation or the estimated parameters that produced a least squares equation were unreasonable. The two soils had very low total carbon and nitrogen and only a negligible amount of potentially mineralizable nitrogen. Because the behavior of these two soils was so different from all others in the study, we excluded them from statistical analysis.

Potential nitrogen mineralization was measured in the laboratory by incubating soil samples in microlysimeters under controlled conditions (Stanford and Smith 1972, Nadelhoffer 1990). Samples from the top $12 \mathrm{~cm}$ of the soil profile were collected in October 1995 from each control and exclosure plot, dried, and sieved. We put 30-g (drymass) subsamples of each soil into separate microlysimeters and incubated them in a dark, $30^{\circ} \mathrm{C}$ environmental chamber for $40 \mathrm{wk}$.
During the initial weeks of the incubation, we extracted inorganic nitrogen from soil samples weekly by leaching each lysimeter with $100 \mathrm{~mL}$ of nutrient extractant solution (Nadelhoffer 1990). After 8 wk, we leached the lysimeters every 2 wk with $80 \mathrm{~mL}$ of nutrient extractant solution. As the nitrogen yield slowed, we leached at less frequent intervals until the last leaching interval of $13 \mathrm{wk}$. To ensure equal soil water tension, each lysimeter was suctioned to a tension of $-0.05 \mathrm{MPa}$ for several minutes after the leachate was added. Ammonium concentration in leachates was measured colorimetrically at $630 \mathrm{~nm}$ by the indophenol blue method. Nitrate was reduced to nitrite with cadmium and was measured colorimetrically at $540 \mathrm{~nm}$ using a diazotized sulfanilimide EDTA method (Greenburg et al. 1992). All colorimetric analyses were done with an Alpkem RFA 300 autoanalyzer (OI Analytical, College Station, Texas, USA).

\section{Hypothesis testing}

Variables that were measured each year were analyzed with a two-factor (treatment and time), blocked (treatments spatially paired) repeated-measures design. Because we were interested in vole removal effects in individual years as well as in time-by-vole effects, we used Tukey's hsd test within the repeated-measure design to assess exclosure effects in individual years. Several control-exclosure pairs were not sampled at Crystal Bench in October 1992. Consequently, repeated-measures analysis on these data could only include six replicates, and the repeated-measure analysis lacked power. These data were analyzed with blocked, oneway ANOVA on each year's data separately; the resulting probabilities were evaluated against a Bonferroni-adjusted alpha value of 0.05 . Variables that were not measured repeatedly were analyzed with blocked, one-way ANOVA. All statistical calculations were done with SYSTAT v. 5.1 (SPSS, Chicago, Illinois, USA).

\section{RESULTS}

\section{Small-mammal density}

Three small-mammal species represented $95 \%$ of all individuals captured. Deer mice (Peromyscus maniculatus) and jumping mice (Zapus princeps) were frequently found at both Blacktail and Crystal. Total mouse densities remained fairly stable (5-15 individuals/ha) at both sites throughout the study. Except for one long-tailed vole (Microtus longicaudus) and one water vole (Microtus richardsoni), all microtine rodents caught were montane voles (Microtus montanus). Vole densities were high ( $>50$ individuals/ha) at both sites in 1992 (Fig. 2). Vole populations remained high at Crystal Bench in 1993, whereas the Blacktail population declined. Only the Blacktail site had a measurable vole population in 1994 and 1995. 


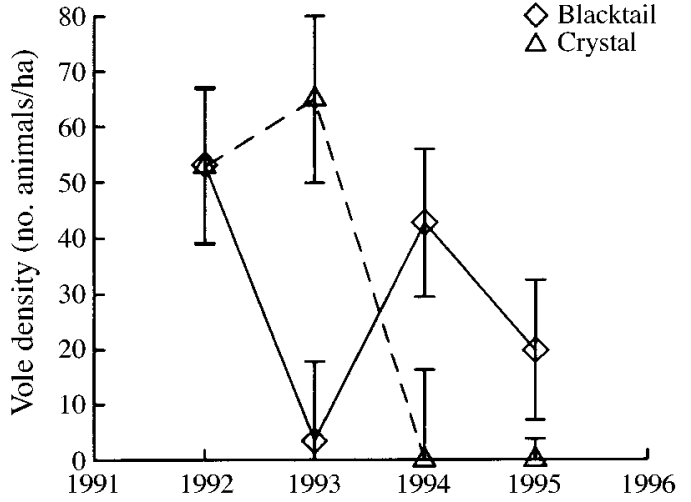

FIG. 2. Estimated vole (Microtus spp.) densities at three sites in the northern range of Yellowstone Park. Data are from live-trapping two mini-grids per site in September of each year. Error bars represent \pm 1 SE of the $y$ estimate.

\section{Effects of vole herbivory on plant litter and community composition}

Early in the study, when vole densities were high, standing dead litter biomass was greater inside exclosures than in plots accessible to voles at Crystal, and was marginally greater at Blacktail (Fig. 3). Across all years, litter biomass was greater in exclosures than in the presence of voles at Blacktail (Fig. 3, Table 2).

Early in the study, plant community composition did not differ between vole exclosures and control plots. By 1995, nitrogen-fixing legumes (Trifolium spp.) were more abundant in plots from which voles were excluded than in control plots at Blacktail, where the combined biomass of Trifolium hybridum and T. longipes in vole exclosures increased by over an order of magnitude, from $<1 \%$ of the total aboveground biomass in 1992 to $13 \%$ in 1995 (Fig. 4). Trifolium biomass was greater in vole exclosures than in control plots at Crystal in 1994, but was small compared to Blacktail.

Initially, the concentration of nitrogen in plant litter did not differ between exclosures and control plots at Crystal. By 1995, however, nitrogen concentration was marginally greater and $\mathrm{C}: \mathrm{N}$ was significantly lower in the presence of voles than in plots without voles (Fig. 3 ). These results were consistent with our predictions that vole herbivory would decrease the $\mathrm{C}: \mathrm{N}$ ratio of plant litter. However, at Blacktail, repeated-measures ANOVA indicated that the pattern of change in litter nitrogen concentration over time differed between control and exclosure plots (Fig. 3, Table 2). The removal of voles at Blacktail caused an increase in the nitrogen concentration of plant litter, but only after several years, as the relative abundance of legumes increased in the absence of vole herbivory.

\section{Laboratory measurement of potentially mineralizable nitrogen}

Approximately twice as much nitrogen was mineralized over the 40-wk incubation from Crystal Bench soil as was mineralized from Blacktail soil (Fig. 5). Despite the large variation between sites in the absolute amount of nitrogen mineralized, most lysimeters mineralized between $4 \%$ and $7 \%$ of the total nitrogen in the soil. The pattern of cumulative yield of mineral nitrogen over time was best fit with the mixed exponential-linear model (Eq. 3), explaining $>99.6 \%$ of the variation in both absolute and proportional nitrogen mineralization. We used Eq. 3 to estimate $N_{0}$ for all lysimeters. Consistent with our hypotheses, removal of voles caused a decrease in the rapidly mineralizable pool at Crystal. For Crystal Bench soils, this pool $\left(N_{0}\right.$, measured in $\mathrm{mg} \mathrm{N} / \mathrm{kg}$ soil) was $27 \%$ larger in plots accessible to voles (238 mg N/kg soil) than in exclosures (187.5 mg N/kg soil; Table 3 ). However, at Blacktail, removal of voles caused an increase in rapidly mineralizable nitrogen. Although there was no statistical difference in absolute $N_{0}, 3.17 \%$ of the total nitrogen in control soils was in the rapidly mineralizable pool, which was $15 \%$ less, a statistically significant difference, than the $3.74 \%$ in soils from plots that had voles removed (Table 3).

\section{DISCUSSION}

Soil organic matter is an important integrating pool linking herbivore activities and nitrogen availability (Ruess and McNaughton 1987, Pastor et al. 1988, Holland and Detling 1990, Frank et al. 1994, Frank and Evans 1997, de Mazancourt et al. 1998, Frank and Groffman 1998) (Fig. 1). The soil organic matter pool is expected to be sensitive to herbivore effects because it integrates processes such as waste deposition, changes in plant growth and nutrient allocation patterns, and the decomposition environment, which may be affected by herbivores. Laboratory incubation of soil is a powerful tool to assess the net effects of herbivores on organic matter quality, because it eliminates the environmental variability that increases sample variance and decreases the power to detect differences in field incubations.

Many studies have documented the stimulation of nitrogen cycling by herbivores (e.g., Ruess and McNaughton 1987, Frank and Groffman 1998), and some have reported a deceleration of nitrogen cycling as an indirect consequence of selective herbivory (Pastor et al. 1993, Ritchie et al. 1998), but no studies have examined both mechanisms simultaneously in a site. We found that the net effect of vole herbivory on soil organic matter quality differed between two study sites. At Crystal, voles were responsible for inputs of low $\mathrm{C}: \mathrm{N}$ plant litter into the soil organic matter, keeping the pool of rapidly mineralizable nitrogen larger than it would be in the absence of voles. Fertilizer effects of vole urine and feces also probably contributed to this effect. These differences in litter quality and rapidly mineralizable nitrogen pools were evident in 1995 , even though vole densities at Crystal were very low in both 1994 and 1995, possibly reflecting a time lag be- 

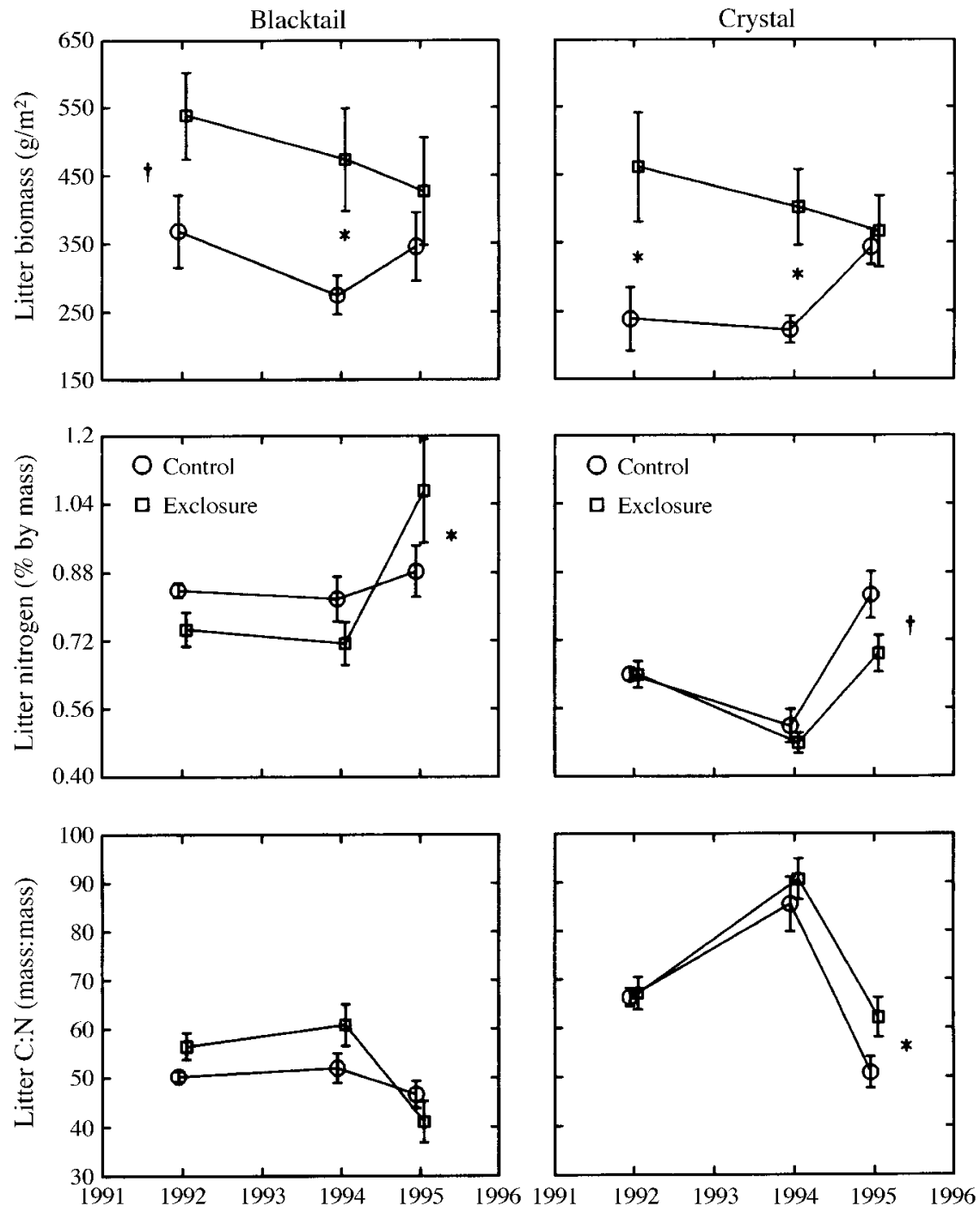

FIG. 3. Mean ( $\pm 1 \mathrm{SE})$ biomass, nitrogen content, and C:N ratio of standing dead plant litter at the end of the growing season, after plant senescence. For Blacktail data, differences between experimental and control means within a year were tested using Tukey's hsd test (test statistic $Q$ calculated with the error term from repeated-measures ANOVA). For Crystal data, because repeated-measures ANOVA could not be performed due to missing data, differences between means were tested using Bonferroni-adjusted individual ANOVAs on each year's data. For all treatments and years, $n=8$, except for Crystal 1992, where $n=6$.

$\dagger P<0.10$.

$* P<0.05$.

TABle 2. Results of two-way repeated-measures ANOVA. Plots (exclosure or control) were sampled yearly from 1992 to 1995 (excluding October litter, which was not sampled in 1993).

\begin{tabular}{cllrcc}
\hline \hline Site & \multicolumn{1}{c}{ Dependent variable } & \multicolumn{1}{c}{ Factor } & \multicolumn{1}{c}{$\mathrm{df}$} & $P$ \\
\hline Blacktail & Oct. litter biomass $\left(\mathrm{g} / \mathrm{m}^{2}\right)$ & Exclosure treatment & 15.95 & 1,14 & 0.001 \\
Blacktail & Oct. litter N concentration (\% by mass) & Exclosure $\times$ Year & 3.35 & 2,28 & 0.050 \\
Blacktail & Oct. litter C:N (mass:mass) & Exclosure $\times$ Year & 2.76 & 2,28 & 0.080 \\
Blacktail & Trifolium biomass (\% of total) & Exclosure treatment & 5.18 & 1,14 & 0.039 \\
\hline
\end{tabular}

Notes: Group means and standard errors are presented in Figs. 3 and 4. All variables and factors yielding $P$ values of 0.10 or less are included in the table; $n=8$ per treatment per year. 


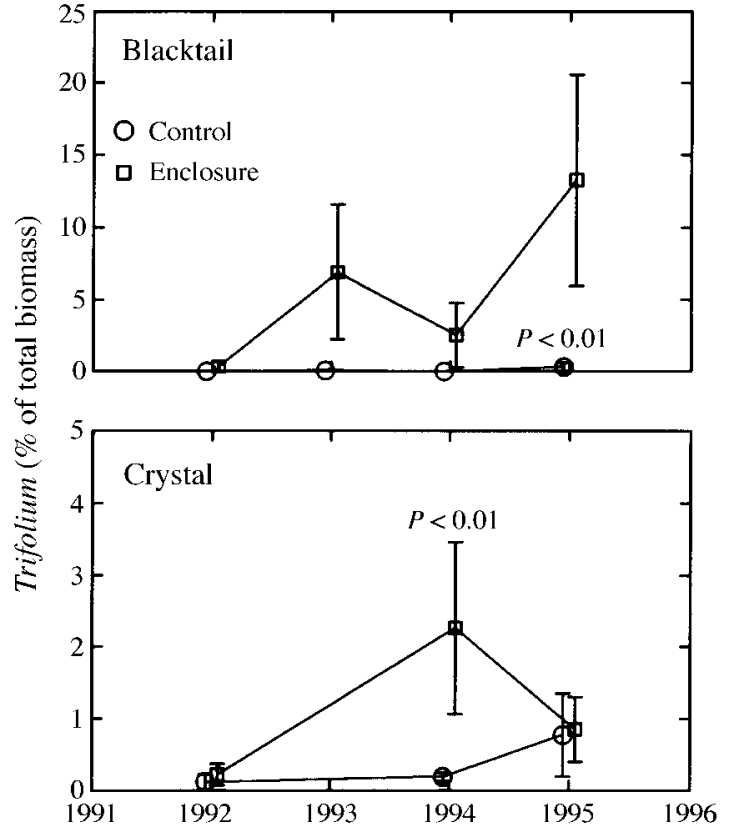

FIG. 4. Relative biomass (percentage of peak aboveground biomass) of Trifolium spp. at Blacktail and Crystal. $P$ values are probabilities associated with Tukey's hsd test $(Q$ calculated with the error term from repeated-measures ANOVA) for treatment differences within each year's data. Only $P$ values $<0.10$ are reported. Error bars represent $\pm 1 \mathrm{SE} ; n$ $=8$ for all years and treatments.

tween initial increases in litter quality and the appearance of this plant litter material in the soil organic matter pool. At Blacktail, however, the direct stimulating effects of vole herbivory on nitrogen cycling were overshadowed by herbivore-mediated changes in plant community composition. Removal of voles caused an increase in high-quality (high-nitrogen) plant litter entering the soil organic matter, which increased the pool of rapidly mineralizable nitrogen in the ab-
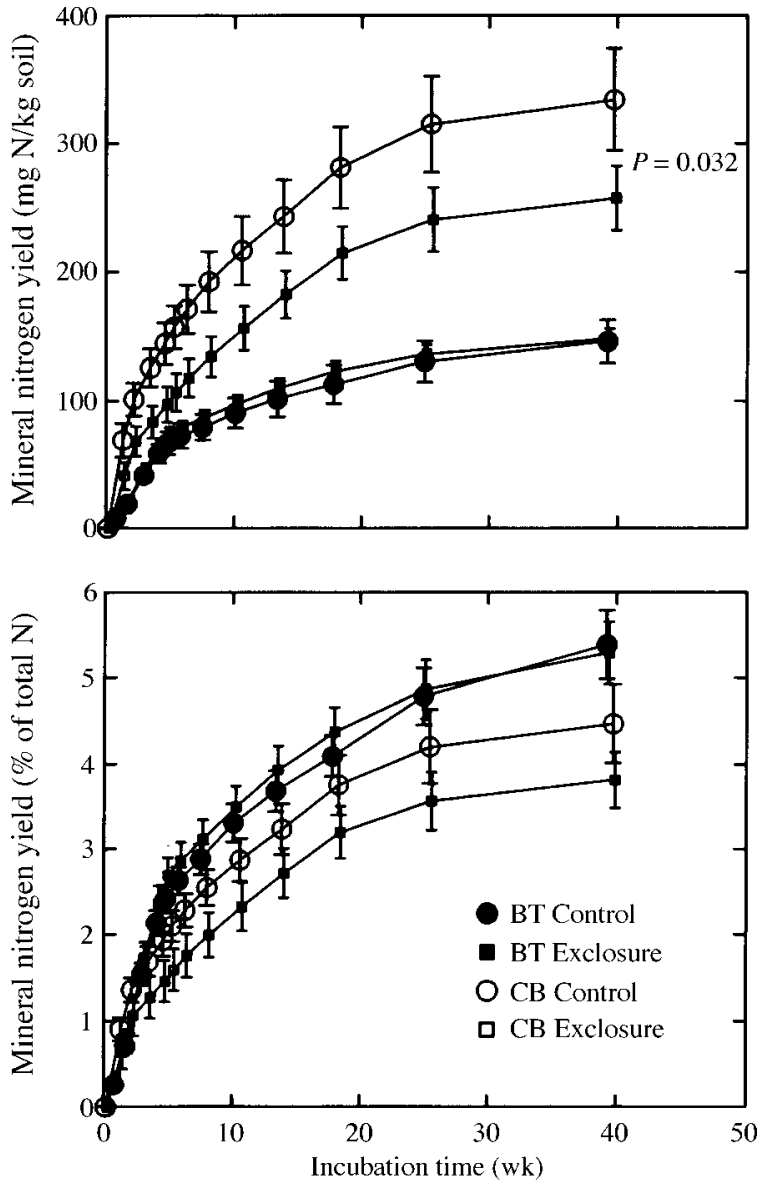

FIG. 5. Cumulative laboratory mineralization $\left(\mathrm{NO}_{3}{ }^{-}+\right.$ $\mathrm{NH}_{4}{ }^{+}$) of soils collected in 1995 from Blacktail (BT) and Crystal (CB) controls and exclosures: top, absolute mineralization; bottom, mineralization as a percentage of total nitrogen in the soil. The $P$ value is associated with the treatment effect of blocked ANOVA on cumulative nitrogen yield (Crystal) at the end of the experiment $(F=8.87$; df $=1,5)$. Means for Crystal control plots exclude two outliers; otherwise, $n=8$; error bars represent \pm 1 SE.

TABLE 3. Mean parameter estimates (with $1 \mathrm{SE}$ in parentheses), both in absolute terms (mg $\mathrm{N} / \mathrm{kg}$ soil) and proportional terms (\% of the total soil $\mathrm{N}$ that is in the rapidly mineralizing pool), of the exponential/linear model (Eq. 3: $N_{t}=N_{0}\left[1-e^{-k t}\right]+C t$ ) from nonlinear curvefitting.

\begin{tabular}{lclcccc}
\hline \hline Site & Dependent & Treatment & \multicolumn{1}{c}{$N_{0}$} & $k$ & \multicolumn{1}{c}{$C$} & $R^{2}$ \\
\hline BT & $\mathrm{mg} \mathrm{N} / \mathrm{kg} \mathrm{soil}$ & control & $89.4(14.6)$ & $0.181(0.009)$ & $1.54(0.23)$ & 0.996 \\
$\mathrm{BT}$ & $\mathrm{mg} \mathrm{N} / \mathrm{kg} \mathrm{soil}$ & exclosure & $105.4(8.5)$ & $0.182(0.014)$ & $1.18(0.10)$ & 0.997 \\
$\mathrm{BT}$ & $\%$ of total N & control & $3.17(0.19) \dagger$ & $0.181(0.009)$ & $0.060(0.009)$ & 0.997 \\
$\mathrm{BT}$ & $\%$ of total N & exclosure & $3.74(0.27) \dagger$ & $0.182(0.014)$ & $0.043(0.006)$ & 0.997 \\
$\mathrm{CB}$ & $\mathrm{mg} \mathrm{N} / \mathrm{kg} \mathrm{soil}$ & control & $237.6(29.2) \ddagger$ & $0.200(0.021)$ & $2.50(0.59)$ & 0.996 \\
$\mathrm{CB}$ & $\mathrm{mg} \mathrm{N} / \mathrm{kg} \mathrm{soil}$ & exclosure & $187.5(19.1) \ddagger$ & $0.162(0.028)$ & $1.99(0.34)$ & 0.997 \\
$\mathrm{CB}$ & $\%$ of total N & control & $3.17(0.32)$ & $0.200(0.021)$ & $0.031(0.005)$ & 0.996 \\
CB & $\%$ of total N & exclosure & $2.80(0.29)$ & $0.162(0.028)$ & $0.029(0.004)$ & 0.997 \\
\hline
\end{tabular}

Notes: Site abbreviations are $\mathrm{BT}=$ Blacktail and $\mathrm{CB}=$ Crystal Bench. Units of $N_{0}$ and $C$ are the same as the dependent variable $\left(N_{t}\right)$, with $C$ being per week; $k$ is a unitless nonlinear rate constant, and $t$ is the incubation time (weeks). Standard errors for $R^{2}$ were less than 0.001 for all data sets. The control means for Crystal soils exclude two outliers; $n=8$ for all means except Crystal controls, where $n=6$.

$\dagger$ Treatment effect significant (blocked ANOVA, $F=8.67, \mathrm{df}=1,5, P=0.032$ ).

$\$$ Treatment effect significant (blocked ANOVA, $F=5.93, \mathrm{df}=1,7, P=0.045$ ). 
sence of voles relative to that of soil from vole-accessible plots.

Small mammals commonly change plant community composition (Summerhayes 1941, Huntly 1987, 1991, Noy-Meir 1988, Moen et al. 1993, Virtanen et al. 1997). Selective consumption of plants with high nitrogen concentration, low $\mathrm{C}: \mathrm{N}$ ratio, or low concentrations of secondary chemicals is one mechanism by which plant community composition can be changed. Many herbivores select plants with high nitrogen concentrations, especially legumes, as preferred forage (Thompson 1965, Mattson 1980, Ritchie et al. 1998), giving less preferred plants competitive advantages over species that are consumed by herbivores. The possibility that changes in plant community composition lead to changes in nutrient dynamics in these systems deserves more consideration.

Why do statistically significant differences exist only in the absolute pool size of rapidly mineralizable nitrogen at Crystal, and in the proportional pool size at Blacktail, when the directional response of absolute and proportional pools to exclosure treatment was similar within each site? At Crystal, the rapidly mineralizable pool decreased $21 \%$ and the proportion of soil nitrogen that was rapidly mineralizable decreased $12 \%$ in the absence of voles, yet only the absolute pool size differed significantly in response to vole exclosure (Table 1). At Blacktail, both means increased by $\sim 18 \%$ when voles were removed, but only the change in the proportion of total $\mathrm{N}$ that was in the rapidly mineralizable pool increased significantly. At Blacktail, the variation in the proportional $N_{0}$ was small compared to the variation in absolute $N_{0}$, so there was more power to detect this difference relative to the difference in absolute $N_{0}$. At Crystal, the variances of these two variables were similar, but the decrease in absolute pool size in response to vole removal was nearly twice as large as the decrease in the proportion rapidly mineralizable nitrogen. This suggests that the changes in response to vole removal at Crystal were primarily the result of decreased flow of nitrogen into the soil organic matter pool, rather than a large change in organic matter quality. For example, the increased biomass of standing dead litter in exclosures, compared to unexclosed plots, represents a pool of nitrogen that is not available for decomposition and has not entered the soil organic matter pool.

The rate at which nitrogen is mineralized from the soil organic matter pool is an important rate-limiting step in the cycling of nitrogen in terrestrial systems (Whitmore and Handayanto 1997). The net effect of herbivores on nitrogen flux depends upon the relative strength of direct and indirect mechanisms that affect mineralization in soil organic matter, and the balance of these no doubt varies through time and space. The appearance of important indirect effects at Blacktail, but not at Crystal, attests that the dominant mechanisms by which herbivores control nitrogen dynamics vary

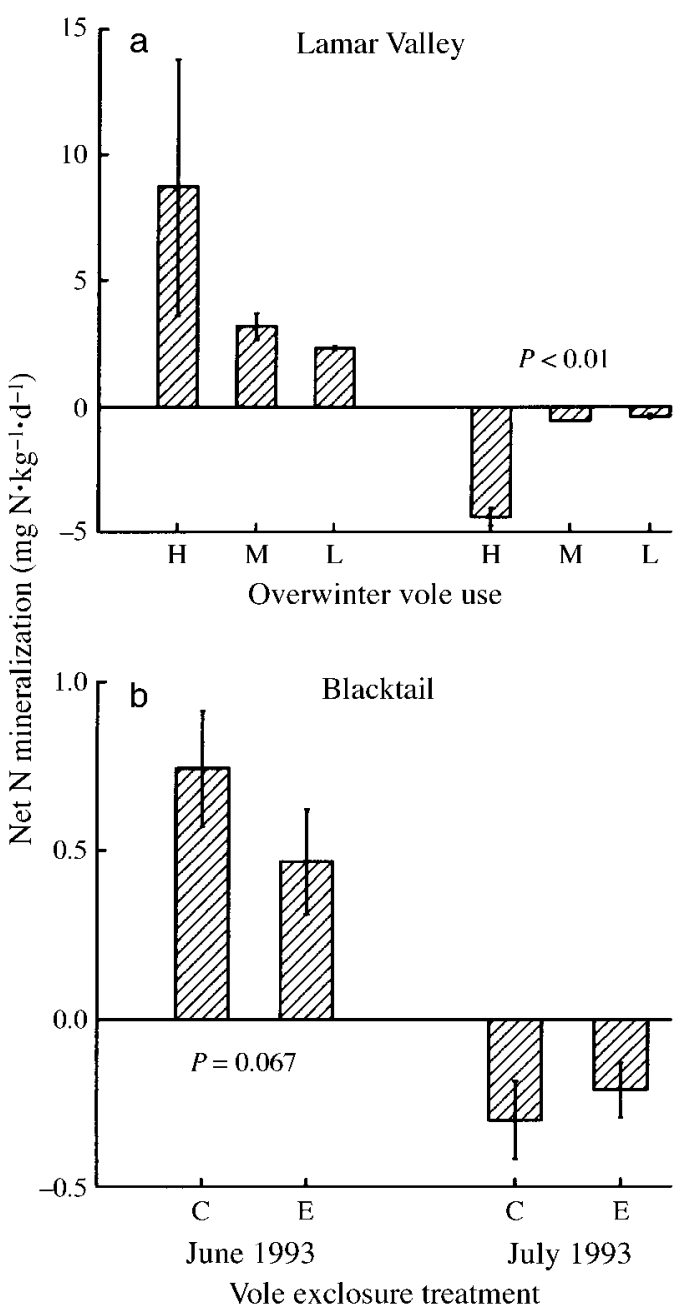

FIG. 6. Net nitrogen mineralization measured in the field during the growing season following a vole population peak at two riparian sites in northern Yellowstone Park. Methods are after Adams and Attiwill (1986) and Frank et al. (1994). (a) Month-long nitrogen mineralization $\left(\mathrm{NO}_{3}{ }^{-}+\mathrm{NH}_{4}{ }^{+}\right)$during June and July 1993 at Lamar Valley (a riparian site in northern Yellowstone Park), on plots that experienced high $(\mathrm{H})$, medium (M), and low (L) vole use over the 1992-1993 winter. (b) Month-long nitrogen mineralization in control plots (C) and exclosures (E) at Blacktail in 1993. $P$ values are from one-way, blocked ANOVA. All probabilities less than 0.10 are shown; $n=3$ at Lamar Valley, and $n=8$ at Blacktail. Error bars are $\pm 1 \mathrm{SE}$.

spatially. In addition, we hypothesize that, in the voleriparian system, the relative importance of direct and indirect mechanisms may vary over time, correlated with changes in vole population density. Measurements of net nitrogen mineralization in the field in 1993, immediately following the vole population peak, revealed increased nitrogen mobility in the presence of high vole populations (Fig. 6). These differences were detected despite the high variance in nitrogen mineralization caused by uncontrollable factors in the field, such as local variation in the soil organic $\mathrm{N}$ pool, soil moisture, 
and temperature. A study at the same sites in 1995 , three years after the population peak, revealed no effect of vole removal on nitrogen mineralization in the field. These data suggest that herbivores with cycling or fluctuating populations may provide spikes of increased nitrogen availability during population peaks, independent of the long-term positive or negative effects of herbivores on the rate of nitrogen cycling.

We found differences in the size of the potentially mineralizable nitrogen pool despite finding no significant differences due to exclosure treatment on total soil nitrogen concentration. This emphasizes that most nitrogen mineralization is from a very small pool of active organic nitrogen. Under conditions of moisture and temperature favorable to microbial mineralization, this laboratory incubation yielded a maximum mineralization of $7 \%$ of the total organic nitrogen (Fig. 5). Under field conditions at both Blacktail and Crystal, $<1 \%$ of total nitrogen was mineralized from May to October 1995. Because the proportion of the soil nitrogen that is in a rapidly cycling pool is so small, the $15 \%$ larger fast pool in soil from Blacktail exclosures, relative to control soils, is very likely an important factor in differences in mineral nitrogen availability in the presence and absence of voles.

\section{Conclusions}

We found that voles affected nitrogen dynamics both directly and indirectly. Direct mechanisms included alterations in litter quantity and quality that increased the pool of soil organic nitrogen that was readily mineralizable. However, after several years and contrary to our initial hypotheses, indirect effects of voles became important to nitrogen dynamics. The removal of chronic grazing by voles increased the biomass of preferred food species, which were the most readily decomposable, inside exclosures. When these high-quality (low $\mathrm{C}: \mathrm{N})$ plants increased inside Blacktail exclosures, the quality of soil organic matter also increased. This change resulted in increased potential for nitrogen mineralization in the absence of herbivory. There was little change in plant community composition at Crystal. Litter quality at this site continued to be more heavily influenced by direct effects of herbivory.

The balance of direct and indirect effects of herbivores on nitrogen cycling appears to be a key to understanding whether herbivores accelerate or decelerate nitrogen cycling. This balance may fluctuate through time. For instance, direct effects of voles on nitrogen cycling occurred as pulses through time, being strong when populations were high, as they were in 1992 and 1993. Indirect effects, resulting from longer term changes in plant community composition, may overshadow direct effects, as we found at the Blacktail site when vole populations were low.

\section{ACKNOWLEDGMENTS}

We thank Steve Howser, Mary Harter, Jen Whipple, and the exclosure-removal crew for their help in the field. Thanks to Bruno Lavettre at Costech for trouble-shooting support. Thanks to Yellowstone National Park personnel for access and permits. Thanks to Richard Inouye and Ken Aho for reviewing this manuscript. This research was supported by NFS grant STI-9413531 and by grants from Sigma Xi, The American Museum of Natural History, and the Graduate Student Research and Scholarship Committee at Idaho State University.

\section{Literature Cited}

Adams, M. A., and P. M. Attiwill. 1986. Nutrient cycling and mineralization in eucalypt forests of south-eastern Australia. 1. Nutrient cycling and nitrogen turnover. Plant and Soil 92:319-339.

Batzli, G. O., and F. A. Pitelka. 1971. Condition and diet of cycling populations of the California vole, Microtus californicus. Journal of Mammalogy 52:141-163.

Bazely, D. R., and R. L. Jefferies. 1985. Goose faeces: a source of nitrogen for plant growth in a grazed salt marsh. Journal of Applied Ecology 22:693-703.

Deans, J. R., J. A. E. Molina, and C. E. Clapp. 1986. Models for predicting potentially mineralizable nitrogen and decomposition rate constants. Soil Science Society of America Journal 50:323-326.

de Mazancourt, C., M. Loreau, and L. Abbadie. 1998. Grazing optimization and nutrient cycling: when do herbivores enhance plant production? Ecology 79:2242-2252.

Frank, D. A., and R. D. Evans. 1997. Effects of native grazers on grassland $\mathrm{N}$ cycling in Yellowstone National Park. Ecology 78:2238-2248.

Frank, D. A., and P. M. Groffman. 1998. Ungulate vs. landscape control of soil $\mathrm{C}$ and $\mathrm{N}$ processes in grasslands of Yellowstone National Park. Ecology 79:2229-2241.

Frank, D. A., R. S. Inouye, N. Huntly, G. W. Minshall, and J. E. Anderson. 1994. The biogeochemistry of a northtemperate grassland with native ungulates: nitrogen dynamics in Yellowstone National Park. Biogeochemistry 26: $163-188$.

Frank, D. A., and S. J. McNaughton. 1992. The ecology of plants, large mammalian herbivores, and drought in Yellowstone National Park. Ecology 73:2043-2058.

Greenburg, A. E., L. S. Clesceri, and A. D. Eaton. 1992. Standard methods for the examination of water and wastewater. Eighteenth edition. American Public Health Association, Washington, D.C., USA.

Holland, E. A., and J. K. Detling. 1990. Plant response to herbivory and belowground nitrogen cycling. Ecology 71: 1040-1049.

Huntly, N. J. 1987. Influence of refuging consumers (pikas: Ochotona princeps) on subalpine meadow vegetation. Ecology 68:274-283.

Huntly, N. J. 1991. Herbivores and the dynamics of communities and ecosystems. Annual Review of Ecology and Systematics 24:477-503.

Knapp, A. K., and T. R. Seastedt. 1986. Detritus accumulation limits productivity of tallgrass prairie. BioScience 36:662-668.

Mack, R. N., and J. N. Thompson. 1982. Evolution in steppe with few large, hooved mammals. American Naturalist 119: 757-773.

Mattson, W. J. 1980. Herbivory in relation to plant nitrogen content. Annual Review of Ecology and Systematics 11: 119-161.

McInnes, P. F., R. J. Naiman, J. Pastor, and J. Cohen. 1992. Effects of moose browsing on vegetation and litter of the boreal forest, Isle Royale, Michigan, USA. Ecology 73: 2059-2075.

McKendrick, J. D., G. O. Batzli, K. R. Everett, and J. C. Swanson. 1980. Some effects of mammalian herbivores and fertilization on tundra soils and vegetation. Arctic and Alpine Research 12:565-578. 
McNaughton, S. J. 1979. Grazing as an optimization process: grass-ungulate relationships in the Serengeti. American Naturalist 113:691-703.

McNaughton, S. J., F. F. Banyikwa, and M. M. McNaughton. 1997. Promotion of the cycling of diet-enhancing nutrients by African grazers. Science 278:1798-1800.

McNaughton, S. J., R. W. Ruess, and S. W. Seagle. 1988. Large mammals and process dynamics in African ecosystems. BioScience 38:794-800.

Merrill, E. H., N. L. Stanton, and J. C. Hak. 1994. Responses of bluebunch wheatgrass, Idaho fescue, and nematodes to ungulate grazing in Yellowstone National Park. Oikos 69: 231-240.

Milchunas, D. G., W. K. Lauenroth, P. L. Chapman, and M. K. Kazempour. 1989. Effects of grazing, topography, and precipitation on the structure of a semiarid grassland. Vegetatio 80:11-23.

Moen, J., P. Lundberg, and L. Oksanen. 1993. Lemming grazing on snow-bed vegetation during a population peak in northern Norway. Arctic and Alpine Research 25:130 135 .

Nadelhoffer, K. J. 1990. Microlysimeter for measuring nitrogen mineralization and microbial respiration in aerobic soil incubations. Soil Science Society of America Journal 54:411-415.

Noy-Meir, I. 1988. Dominant grasses replaced by ruderal forbs in a vole year in undergrazed mediterranean grasslands in Israel. Journal of Biogeography 15:579-587.

Pastor, J., B. Dewey, and D. P. Christian. 1996. Carbon and nutrient mineralization and fungal spore composition of fecal pellets from voles in Minnesota. Ecography 19:5261.

Pastor, J., B. Dewey, R. J. Naiman, P. F. McInnes, and Y Cohen. 1993. Moose browsing and soil fertility in the boreal forests of Isle Royale National Park. Ecology 74: 467-480.

Pastor, J., R. J. Naiman, B. Dewey, and P. McInnes. 1988 Moose, microbes, and the boreal forest. BioScience $\mathbf{3 8}$ : 770-776.

Ruess, R. W. 1987. The role of large herbivores in nutrient cycling of tropical savannahs. Pages 67-91 in B. H. Walker, editor. Determinants of tropical savannahs. IRL Press, Oxford, UK.

Ruess, R. W., and S. J. McNaughton. 1987. Grazing and the dynamics of nutrient and energy regulated microbial processes in the Serengeti grasslands. Oikos 49:101-110.
Ritchie, M. E., D. Tilman, and J. M. H. Knops. 1998. Herbivore effects on plant and nitrogen dynamics in oak savanna. Ecology 79:165-177.

Scott, N. A., and D. Binkley. 1997. Foliage litter quality and annual net $\mathrm{N}$ mineralization: comparison across North American forest sites. Oecologia 111:151-159.

Seastedt, T. R. 1985. Maximization of primary and secondary productivity by grazers. American Naturalist 126:559-564.

Seastedt, T. R., R. A. Ramundo, and D. C. Hays. 1988. Maximization of densities of soil animals by foliage herbivory: empirical evidence, graphical and conceptual models. Oikos 51:243-248.

Shariff, A. R., M. E. Biondini, and C. E. Grygiel. 1994. Grazing intensity effects on litter decomposition and soil nitrogen mineralization. Journal of Range Management 47: 444-449.

Stanford, G., and S. J. Smith. 1972. Nitrogen mineralization potential of soils. Soil Science Society of America Proceedings 36:465-472.

Summerhayes, V. S. 1941. The effects of voles (Microtus agrestis) on vegetation. Journal of Ecology 29:14-48.

Swank, W. T., J. B. Waide, D. A. J. Crossley, and R. L. Todd. 1981. Insect defoliation enhances nitrate export from forested ecosystems. Oecologia 51:297-299.

Taitt, M. J., and C. J. Krebs. 1985. Population dynamics and cycles. Pages 567-620 in R. H. Tamarin, editor. Biology of New World Microtus. American Society of Mammalogists, Special Publication 8.

Tardiff, S. E., and J. A. Stanford. 1998. Grizzly bear digging: effects on subalpine meadow plants in relation to mineral nitrogen availability. Ecology 79:2219-2228.

Taylor, B. R., D. Parkinson, and W. F. J. Parsons. 1989. Nitrogen and lignin content as predictors of litter decay rates: a microcosm test. Ecology 70:97-104.

Thompson, D. Q. 1965. Food preferences of meadow vole (Microtus pennsylvanicus) in relation to habitat affinities. American Midland Naturalist 74:76-86.

Virtanen, R., H. Henttonen, and K. Laine. 1997. Lemming grazing and structure of a snowbed plant community-a long-term experiment at Kilpisjarvi, Finnish Lapland. Oikos 79:155-166.

Whitmore, A. P., and E. Handayanto. 1997. Simulating the mineralization of $\mathrm{N}$ from crop residues in relation to residue quality. Pages 337-348 in G. Cadisch and K. E. Giller, editors. Driven by nature: plant litter quality and decomposition. CAB International, Wallingford, UK. 